\title{
BMJ Open Translation of the international outcome inventory for hearing aids into Portuguese from Portugal
}

\author{
Sofia M M Paiva, ${ }^{1}$ João F C P M Simões, ${ }^{1}$ António M Diogo Paiva, ${ }^{1}$ \\ Francisco J F Castro e Sousa, ${ }^{2}$ Jean-Pierre Bébéar ${ }^{3}$
}

To cite: Paiva SMM, Simões JFCPM, Paiva AMD, et al. Translation of the international outcome inventory for hearing aids into Portuguese from Portugal. BMJ Open 2017;7: e013784. doi:10.1136/ bmjopen-2016-013784

- Prepublication history and additional material is available. To view please visit the journal (http://dx.doi.org/ 10.1136/bmjopen-2016013784).

Received 9 August 2016 Revised 9 February 2017 Accepted 13 February 2017

\section{CrossMark}

\section{${ }^{1}$ Department of}

Otorhinolaryngology, Coimbra Hospital and University Centre, Coimbra, Portugal ${ }^{2}$ Department of General Surgery, Coimbra Hospital and University Centre, Coimbra, Portugal

${ }^{3}$ Department of Otorhinolaryngology, Clinique Universitaire ORL de Bordeaux II, Bordeaux France

Correspondence to Dr Sofia M M Paiva; sofpaiva@gmail.com

\section{ABSTRACT}

Objective: To translate the International Outcome Inventory for Hearing Aids (IOI-HA) Questionnaire from English to Portuguese (from Portugal) and to validate this instrument of study on the Portuguese population. Design: In this prospective study, a translation from English into Portuguese of the IOI-HA was performed, and linguistic adaptation and counter translation were also accomplished. The data were analysed for internal consistency testing for correlations between each individual item and the total score of the IOI-HA, assessing the Cronbach $\alpha$ and performing test-retest analysis.

Setting and participants: 80 hearing aid users aged 18 years or older were recruited from an ear, nose and throat (ENT) appointment in Coimbra's hospital, Portugal. $84 \%$ of the participants were unilateral hearing aid users, whereas $16 \%$ were bilateral users.

Interventions: The patients volunteered to answer the questionnaire during an ENT appointment. All of the patients had been using the hearing aids for more than 3 years.

After the first application of the questionnaire, a new appointment was planned for retesting, within at least 7 days to no more than 60 days. 29 participants answered the questionnaire again according to the same procedure.

Results: The mean IOI-HA total score in the study population was $27.33 \pm 4.93(9-35)$. The mean values obtained for each item of the questionnaire ranged from 3.19 to 4.54. The Cronbach $\alpha$ was 0.838 and the Cronbach $\alpha$ values when the item was removed, were also significantly strong. The test-retest analysis revealed no differences between the paired groups.

Conclusions: In the present study a valid and reliable translation and adaptation of the IOI-HA into Portuguese from Portugal is proposed. This tool will be available for clinical assessment of hearing aid users.

\section{INTRODUCTION}

The International Outcome Inventory for Hearing Aids (IOI-HA) is a questionnaire developed to quantify the satisfaction of

\section{Strengths and limitations of this study}

- Translation and validation of the International Outcome Inventory for Hearing Aids (IOI-HA) Questionnaire from English to Portuguese from Portugal and the Portuguese population.

- Prospective study, linguistic adaptation and counter translation accomplished.

- The data were analysed for correlations between each individual item and the total score of the IOI-HA.

- Internal consistency was assessed with the Cronbach $\alpha$ coefficient with test-retest analysis.

- A Brazilian version of this questionnaire has been published previously; Brazilian is a variation of the Portuguese language and is different in several aspects from the language spoken and written in Portugal; an analysis of results between the two different versions on the Portuguese population would have been interesting. This could be an opportunity for a follow-up validation study.

hearing aid users (HAUs) and the impact these devices have on their lives. ${ }^{1}$ The IOI-HA is an international standardised selfreport measure. ${ }^{2}$ Recent research supports the advantages of its use in the rehabilitation process of HAUs. ${ }^{3}$

The IOI-HA contains seven questions used to subjectively evaluate the results of the hearing aids under the following parameters: (1) time for which hearing aids have been used; (2) benefit; (3) residual limitation in daily life activities; (4) satisfaction; (5) residual restrictions to participation; (6) impact on other people; and (7) quality of life. The answers to each question range from poor performance (1) to best performance (5). ${ }^{3}$ Previous studies have shown that the IOI-HA can be used administratively to record the outcomes of a service facility, as a research instrument and an advisor for potential deficits that need to be improved. ${ }^{1}$ The IOI-HA has been translated and validated into 27 different languages. 
The validation of the IOA-HA in Portuguese from Brazil (Brazilian) was published in $2010^{3}$ and is known as the QI-AA (Questionário Internacional-Aparelhos Auditivos). Brazilian Portuguese is a variant of the original Portuguese language, spoken in South America, which has significant differences from the European Portuguese spoken in Portugal and in other Portuguese-speaking countries. These differences are for example, how words sound (phonology), the use of gerund in verbs, and, most important, in vocabulary (eg, hearing aids is 'aparelhos auditivos' in Portuguese and 'aparelhos de amplificação sonora' in Brazilian). These differences can have a tremendous influence when using questionnaires like the IOI-HA, influencing the validation trial of this tool. Therefore, the purpose of the present study was to assess the internal consistency of the IOI-HA translated into Portuguese from Portugal, and to validate this instrument of study on the Portuguese population. It is fundamental to analyse the psychometric properties of this tool so that its results can be accurately and reliably interpreted.

\section{MATERIALS AND METHODS}

This prospective study was carried out at the ENT (Ear, Nose and Throat) Department of Coimbra University Hospitals and was approved by the Ethics in Research Committee of this institution. We began our work by translating the IOI-HA (see online supplementary appendix 1) from English to Portuguese (from Portugal), according to the guidelines for translation provided by the International Collegium of Rehabilitative Audiology. ${ }^{4}$ The complete translation included not only the items or questions and the instructions, answers, but also the overall format of the questionnaire. All of these were carefully reproduced from the original English version in order to produce an accurate translation. The steps of this process were as follows: First, an individual who was well versed in Audiology and hearing aids and who had Portuguese as his/her first language performed the translation from English to Portuguese. The translator carefully followed the design principles of the original version. Second, this translation was then 'back-translated' from Portuguese into English. The back-translation was performed by a third individual; this person was unaware of the original wording and was very fluent in both languages. Third, the back-translation was then checked against the original wording to ensure that each translated item captured the nuances of the original English wording.

Eighty HAUs aged 18 years or older from the ear, nose and throat (ENT) Department of Coimbra University Hospitals, without cognitive disorders, answered the questionnaire (see online supplementary appendix 2) during an ENT appointment. The mean age of the patients was 68.1 years \pm 11.2 (36-96), $57.5 \%$ were female patients and $42.5 \%$ male patients.

We ruled out any cognitive disorder based on basic questions (eg day and month of the year, location, date of birth) during the interview. The patients included in this study answered the questionnaire in person and did not have any help from the assistant; we reviewed the answers for completeness. Instructions were included in the text preceding each question, and the subjects could select only one answer for each question. All of the subjects had been using the hearing aids for more than 3 years. In Portugal, hearing aids are prescribed by a ENT doctor and can be acquired by the patients themselves or they can be provided by the National Health Care Service.

After the appointment, the patients were submitted to a pure tone and pure bone audiogram followed by a speech audiogram with and without the hearing aid.

During the follow-up period, the HAUs performed an aided audiogram (open field, with the speakerphones on $90^{\circ}$ and $270^{\circ}$ azimuth).

The unilateral HAUs had the other ear opened. The aided audiogram was important to quantify the audiometric gain of the patients when using the hearing aids.

After the first application of the questionnaire, a new appointment was planned for retesting, within at least 7 days to no more than 60 days. Twenty-seven participants answered the questionnaire again according to the same procedure, and they did not have access to the answers they had given the first time.

Data collected from the IOI-HA were converted into numeric values and analysed using Statistical Package for the Social Sciences software (SPSS), V.21. An independent t-test was used to detect differences in IOI-HA scores between genders and the results obtained from testing-retesting were analysed and compared using the paired t-test. The correlation between each individual item of the IOI-HA and between pure tone average (PTA) and IOI-HA scores was tested with the Pearson correlation ratio with a level of significance set at $5 \%$. This analysis provides very important information about the discrimination capacity of each question. Moreover, the Cronbach $\alpha$ coefficient, defined as the level of homogeneity between the different items of the questionnaire was also assessed. Values higher than 0.70 were considered adequate.

Table 1 Mean values, SDs obtained in each item of the questionnaire, corrected item-total correlation and Cronbach $\alpha$ if each item is removed and for the questionnaire as a whole

\begin{tabular}{lrrll}
\hline Question & Mean & SD & $\begin{array}{l}\text { Corrected } \\
\text { item-total } \\
\text { correlation }\end{array}$ & $\begin{array}{l}\text { Cronbach } \\
\boldsymbol{\alpha} \text { if item is } \\
\text { removed }\end{array}$ \\
\hline Q1 & 4.54 & 0.84 & 0.441 & 0.836 \\
Q2 & 3.88 & 1.02 & 0.774 & 0.785 \\
Q3 & 3.19 & 1.04 & 0.668 & 0.803 \\
Q4 & 4.08 & 1.04 & 0.729 & 0.793 \\
Q5 & 3.91 & 1.02 & 0.555 & 0.821 \\
Q6 & 3.98 & 1.13 & 0.292 & 0.865 \\
Q7 & 3.75 & 0.97 & 0.728 & 0.794 \\
Total & 27.33 & 7.06 & - & 0.838 \\
\hline
\end{tabular}




\section{RESULTS}

Eighty-four per cent of the participants were unilateral HAUs, whereas $16 \%$ were bilateral users.

The mean pure tone average before amplification was $56 \pm 20 \mathrm{~dB}$ HL (29-116). The mean of the total score of the IOI-HA in the studied population was $27.33 \pm 4.93$ $(9-35)$.

The mean values for each item of the questionnaire and the correlation with the total score are presented in table 1 . This table also includes the values of Cronbach $\alpha$ if each item is removed and for the questionnaire as a whole. The Cronbach $\alpha$ value was 0.838 , suggesting that the items have high internal consistency.

Table 2 presents the correlation between each item, which was statistically significant in the majority of the cases. Finally, table 3 contains the test-retest reliability of the IOI-HA and the correlation between answers in both test applications. The correlation between the test and retest application is strong, with no statistical differences between each question $(p>0.05)$.

\section{DISCUSSION}

Study reliability is the degree at which the measured result reflects the true result; this study evaluated the internal consistency of the Portuguese version of the IOI-HA, translated into Portuguese from Portugal.

The IOI-HA has been translated into various languages allowing its standardised use across countries and linguistic communities. The use of this questionnaire as a self-assessment tool is extremely important as user satisfaction is closely related to the success of rehabilitation. The results of this study demonstrate that the use of the questionnaire was adequate, simple and easy to apply and that it can be used as a measure of self-perception. It can also be used to evaluate measures as speech perception and sound quality.

The mean value for each item varied between 3.19 and 4.54. These values highlight a good level of
Table 3 Test-retest results (significant if ${ }^{*} p<0.05$ )

\begin{tabular}{|c|c|c|c|}
\hline Question & $\begin{array}{l}\text { Difference } \\
\text { between } \\
\text { mean values }\end{array}$ & $\begin{array}{l}\text { Paired } \\
\text { t-test } \\
\text { p Value }\end{array}$ & $\begin{array}{l}\text { Correlation } \\
\text { between items in } \\
\text { both tests } \\
\text { (Pearson's } \\
\text { correlation ratio } \\
\text { and p value) }\end{array}$ \\
\hline Q1 & -0.068 & 0.161 & $0.924(<0.001)$ \\
\hline Q2 & -0.034 & 0.573 & $0.956(<0.001)$ \\
\hline Q3 & 0.103 & 0.184 & $0.936(<0.001)$ \\
\hline Q4 & -0.172 & 0.232 & $0.723(<0.001)$ \\
\hline Q5 & -0.103 & 0.184 & $0.888(<0.001)$ \\
\hline Q6 & -0.172 & 0.096 & $0.868(<0.001)$ \\
\hline Q7 & -0.069 & 0.326 & $0.940(<0.001)$ \\
\hline
\end{tabular}

satisfaction with the hearing aids, as it shows favourable attitudes (above $50 \%$ of the total score) towards hearing aids. The literature supports this finding. ${ }^{15-7}$

The distribution of answers shows that few patients selected the answers associated with the poorest outcomes. The data obtained in this study are similar to other studies ${ }^{1} 367^{7}$ and we believe that the IOI-HA is feasible for detection of individuals who are not satisfied with their experience with amplification.

These data suggest that we could use the questionnaire in three ways: administratively to document the outcomes of a service facility (obtaining the total score), as a research instrument (as a two-score index was identified) and as a miniprofile with norms for identifying areas that need to be improved for the patient (if the inventory is used clinically to validate a fitting). ${ }^{1} 67$

Study reliability is a degree in which the measured variables result reflects the true result. We measured the reliability with the internal consistency of the questionnaire as a whole through the Cronbach $\alpha$ that was 0.838 . A higher Cronbach $\alpha$ ratio corresponds to a high internal consistency. ${ }^{8}$ This result is similar to the value

Table 2 Correlation between IOI-HA questions (significant if * $p<0.05$ )

\begin{tabular}{llllllll}
\hline Question & Q1 & Q2 & Q3 & Q4 & Q5 & Q6 & Q7 \\
\hline Q1 & 1.000 & 0.535 & 0.359 & 0.488 & 0.188 & 0.001 & 0.429 \\
p & - & $0.000^{*}$ & $0.001^{*}$ & $0.000^{*}$ & 0.095 & 0.993 & $0.000^{*}$ \\
Q2 & 0.535 & 1.000 & 0.614 & 0.770 & 0.389 & 0.193 & 0.781 \\
p & $0.000^{*}$ & - & $0.000^{*}$ & $0.000^{*}$ & $0.000^{*}$ & 0.086 & $0.000^{*}$ \\
Q3 & 0.359 & 0.614 & 1.000 & 0.569 & 0.490 & 0.249 & 0.581 \\
p & $0.001^{*}$ & $0.000^{*}$ & - & $0.000^{*}$ & $0.000^{*}$ & $0.026^{*}$ & $0.000^{*}$ \\
Q4 & 0.488 & 0.770 & 0.569 & 1.000 & 0.399 & 0.194 & 0.693 \\
p & $0.000^{*}$ & $0.000^{*}$ & $0.000^{*}$ & - & $0.000^{*}$ & 0.084 & $0.000^{*}$ \\
Q5 & 0.188 & 0.389 & 0.490 & 0.399 & 1.000 & 0.489 & 0.423 \\
p & 0.095 & $0.000^{*}$ & $0.000^{*}$ & $0.000^{*}$ & - & $0.000^{*}$ & $0.000^{*}$ \\
Q6 & 0.001 & 0.193 & 0.249 & 0.194 & 0.489 & 1.000 \\
p & 0.993 & 0.086 & $0.026^{*}$ & 0.084 & $0.000^{*}$ & - & 0.189 \\
Q7 & 0.429 & 0.781 & 0.581 & 0.693 & 0.423 & 0.189 \\
p & $0.000^{*}$ & $0.000^{*}$ & $0.000^{*}$ & $0.000^{*}$ & $0.000^{*}$ & 0.094 \\
IOI-HA, International & Outcome Inventory for Hearing Aids. & & & 0.094 \\
\hline
\end{tabular}


observed in the English version $^{1}$ and lower than that of the German version ${ }^{7}$ and it indicates that the translated version is consistent. The test-retest analysis showed no statistically significant difference between groups, reflecting an acceptable reliability.

\section{CONCLUSION}

The purpose of this study was to establish a translation of the Portuguese version of the IOI-HA. From the results, we could see that the questionnaire presents an acceptable reliability. We believe, as also seen in other studies ${ }^{167}$ that the IOI-HA can be used in the rehabilitation process of HAUs. The results show that this instrument of study maintains the utility of its original version.

Acknowledgements The authors wish to express our gratitude to all the audiologists of the Department of Otorhinolaryngology Head and Neck Surgery of Coimbra University Hospital, in Portugal, for their work in and support to this study.

Contributors SMMP made substantial contributions to conception and design, acquisition of data, analysis and interpretation of data, and drafting the article. JFCPMS contributed to analysis and interpretation of data and revising the article. AMDP, FJFCS, J-PB contributed by revising the manuscript critically for important intellectual content and final approval of the version to be published.

Competing interests None declared.

Patient consent Obtained.
Ethics approval This prospective study was held at the ear nose and throat (ENT) Department of Coimbra University Hospitals and was approved by the Ethics in Research Committee of this Institution.

Provenance and peer review Not commissioned; externally peer reviewed.

Data sharing statement No additional data are available.

Open Access This is an Open Access article distributed in accordance with the Creative Commons Attribution Non Commercial (CC BY-NC 4.0) license, which permits others to distribute, remix, adapt, build upon this work noncommercially, and license their derivative works on different terms, provided the original work is properly cited and the use is non-commercial. See: http:// creativecommons.org/licenses/by-nc/4.0/

\section{REFERENCES}

1. Cox RM, Alexander GC. The International Outcome Inventory for Hearing Aids (IOI-HA): psychometric properties of the English version. Int J Audiol 2002;41:30-5.

2. Cox RM, Stephens D, Kramer SE. Translations of the International Outcome inventory for Hearing Aids (IOI-HA). Int J Audiol 2002;41:3-26.

3. Gasparin M, Menegotto IH, Cunha CS. Psychometric properties of the international outcome inventory for hearing AIDS. Braz J Otorhinolaryngol 2010;76(1):85-90.

4. http://icra-audiology.org/Repository/self-report-repository/IOI-HA\% 20list-of-questionnaires. (access date $20 \mathrm{Dec} 2016$ ).

5. Prates LP, lório MC. Aclimatização: estudo do reconhecimento de fala em usuários de próteses auditivas. Pro Fono 2006;18:259-66.

6. Kramer SE, Goverts ST, Dreschler WA, et al. International Outcome Inventory for Hearing Aids (IOI-HA): results from The Netherlands. Int J Audiol 2002;41:36-41.

7. Heuermann $\mathrm{H}$, Kinkel M, Tchorz J. Comparison of psychometric properties of the International Outcome Inventory for Hearing Aids (IOI-HA) in various studies. Int J Audiol 2005;44:102-9.

8. Bisquerra R, Sarriera JC, Matínez F, et al. Introdução à Estatística. Enfoque Informático com Pacote Estatístico SPSS. Porto Alegre: Artmed, 2004. 